\title{
Effect of Macronutrients, Micronutrients and Rhizobium on Growth Parameters in French Bean (Phaseolus Vulgaris L.)
}

\author{
Nitish Kumar Jena*, Ajoy Kumar Pattnaik, Premananda Mahapatra, Alok Nandi, \\ Janmejaya Panda and Asim Abhishek Swain
}

\author{
Department of Horticulture, Institute of Agricultural Sciences, Siksha 'O' Anusandhan \\ (Deemed To Be University) Bhubaneswar-751029, Odisha, India
}

*Corresponding author

\section{A B S T R A C T}

\begin{tabular}{|c|}
\hline Keywords \\
\hline $\begin{array}{l}\text { Legume, French } \\
\text { bean, N:P:K, } \\
\text { Rhizobium, } \\
\text { Micronutrients, } \\
\text { Vegetative growth }\end{array}$ \\
\hline Article Info \\
\hline $\begin{array}{l}\text { Accepted: } \\
\text { 10 March } 2020 \\
\text { Available Online: } \\
10 \text { April } 2020\end{array}$ \\
\hline
\end{tabular}

The present experiment entitled "Effect of macronutrients, micronutrients and rhizobium on growth parameter in French bean (Phaseolus vulgaris L.)" was carried out during Rabi, 2018-19 at Instructional Farm-II of Institute of Agricultural Sciences, Bhubaneswar. The recommended dose of fertilizer (RDF) used for French bean was 50:75:75 NPK kg ha-1 along with FYM @ 15 ton $^{-1}$. The chemical fertilizers were applied in three levels i.e. 50 $\%, 100 \%$ and $150 \%$ of the RDF with various combinations of rhizobium culture and micronutrients. The experiment consisted of twelve treatments in various combinations of different levels of fertilizer with or without rhizobium culture (30 $\mathrm{g} \mathrm{kg}^{-1}$ of seed) and micronutrients $(0.1 \%)$. The results obtained from the present investigation indicated that the treatment receiving 50:75:75 NPK kg ha ${ }^{-1}$ (100\% RDF) along with FYM @ $15 \mathrm{t} \mathrm{ha}^{-1}$, rhizobium culture $\left(30 \mathrm{~g} \mathrm{~kg}^{-1}\right.$ of seed) and micronutrients $(0.1 \%)$ recorded significantly higher values as regards growth characters of French bean var. Harsh. Different parameters like plant height $(47.96 \mathrm{~cm})$, maximum number of branches $(20.17)$, maximum plant spread $(49.75 \mathrm{~cm})$, maximum number of leaves $(17.7)$, maximum leaf area $(163.27 \mathrm{sq} \mathrm{cm})$ were also significantly superior than other treatment combinations tried in this experiment. Thus, it may be suggested that RDF with rhizobium culture and micronutrients application increases maximum vegetative growth in case of French bean.

\section{Introduction}

French bean (Phaseolus vulgaris L.) is one of the most important leguminous vegetables in India. It is the most important dinitrogen fixation system in the nature. It is valued for its protein rich $(23 \%)$ seeds. Globally, common bean is the dominant grain legume of subsistence smallholder farming households, who consume its protein rich pods/beans as green vegetables, immature seeds, and mature seeds. As a whole there is urgent need for increasing the productivity with better quality pods. Hence, proper production technologies are essential to achieve the goal. From among the production technologies, nutrient management plays an important role in this crop. 
Ahmed et al., (2016) studied the influence of Rhizobium inoculation on nodules, growth and yield of three different cultivars of French bean i.e 'Evergreen', 'Komal green' and 'Winner' (Phaseolus vulgaris L.) The Rhizobium inoculation significantly enhanced the growth and yield parameter of French beans cultivars. All the parameters of growth and yield showed best results for synthetic rhizobium inoculation of seeds. Rawat et al., (2018) found that Biofertilizers are substances which contain living microorganisms which when applied to a soil promote the growth by increasing availability of primary nutrients to the host plant.

Their report showed that of isolated rhizobial strain enhanced the growth of plant. The isolated strain can be used as biofertilizer. Tiwari et al., (2017) reported that Rhizobium and Azotobacter sp. effects on the plant growth, nodule appearance, no of leaf, shoot length, root length, chlorophyll contents and carbohydrate content in black gram due to the Azotobacter and Rhizobium sp. have friendly associations and they have different physiology and habitat.

Therefore, they help plant growth promotion by their own system. Kumar et al., (2009) conducted an experiment to study the effect of organic, inorganic and biofertilizers on French bean and found that $25 \% \mathrm{~N}$ organic (recommended dose of $\mathrm{N}$ through vermicompost) to $100 \% \mathrm{NPK}$ (recommended dose of NPK through fertilizers), being at par with $100 \% \mathrm{NPK}+50 \% \mathrm{~N}$ organic resulted in significant improvement in growth character.

In Odisha, practically there are no research work has been conducted with reference to application of rhizobium and micronutrients in French bean. Hence this experiment was undertaken to observe the effects of macronutrients and micronutrients along with rhizobium culture on vegetative growth of French bean.

\section{Materials and Methods}

The present research entitled "Effect of macronutrients, micronutrients and rhizobium on growth parameters in French bean (Phaseolus vulgaris L.)" was conducted during Rabi, 2018-19 at Instructional Farm-II of Institute of Agricultural Sciences, Bhubaneswar. The experiment was carried out to study the effects of rhizobium culture and micro-nutrient at different levels of fertilizer on vegetative growth of French bean. Variety Harsh was selected.

Twelve treatments using different recommended dose of fertilizer (NPK::50:75:75), rhizobium culture (30 $\mathrm{g} \mathrm{kg}^{-1}$ of seed) and micronutrients (0.1\%) were applied in different treatments. The sowing was done in rabi season using RBD. The sowing spacing of $30 \mathrm{~cm} \times 15 \mathrm{~cm}$ in $1.5 \mathrm{~m} \times$ $1.2 \mathrm{~m}$ with total area of $65 \mathrm{~m}^{2}$ for each treatment is done. From each plot five observation plants were selected from each treatment to record the plant height, number of branches per plant, plant spread, number of leaves per plant and leaf area. The details of the treatments applied in this experiment is given in Table 1.

\section{Results and Discussion}

Significant variations were observed in plant height as influenced by rhizobium and micronutrient at $100 \%$ RDF applied to the crop. Significant variations in plant height were recorded at 60 DAS. It ranges from $36.11 \mathrm{~cm}$ to $47.96 \mathrm{~cm}$. Significantly highest plant height of $47.96 \mathrm{~cm}$ was recorded in the treatment receiving 100\% RDF (50:75:75 NPK kg ha ${ }^{-1}$ ) in combination with rhizobium treatment and micronutrient spray $\left(\mathrm{T}_{11}\right)$. The result revealed that plant height in French 
bean was greatly influenced by the combined application of $100 \%$ RDF along with rhizobium and micronutrient. The biofertilizer i.e. rhizobium might have attributed to longer duration of sustained supply of nutrient during the growth period, which also include the micronutrient application. Significant increase in plant height might also be due to the production of different phyto-hormones like IAA, GAA \& cytokinin produced by rhizobium.

The increase of plant height also be due to the growth promoting substances produced by rhizobium help for the height of the plant. Further the chemical fertilizer particularly $\mathrm{N}$ along with the micronutrients after been taken during growth period resulted in quicker cell formation and elongation leading to increase the height of the plant which was presented in Table 2 and Figure 1 on 60 DAS of the crop growth. Similar results in increasing plant height have been reported by Ahmed et al., (2015) and Kumar et al., (2009).

The result on the number of branches per plant recorded at 60DAS is presented in Table 2 and Figure 2. Significantly maximum number of branches (20.17) was recorded in $\mathrm{T}_{11}$ receiving $100 \%$ of $\mathrm{RDF}$ along with rhizobium culture and micronutrients than the rest of the treatments.

The results revealed that the number of branches plant ${ }^{-1}$ was maximum due to the combined application of $100 \%$ RDF with rhizobium and micronutrients as compared to other treatments in this experiment. This clearly indicates that application of recommended doses of chemical fertilizer along with rhizobium and micronutrient got a cumulative effect to enhance the requirement as well as utilization by the crop for development of more number of branches. The nutrient requirement of the plant supplied through recommended dose of fertilizer along with rhizobium and micronutrient, which increased the growth and hence there is development of number of branches per plant. This finding corroborates with the findings of Ahmed et al., (2015) and Kumar et al., (2009).

The spread of French bean plant was also recorded at the same time as in case of plant height and number of branches i.e. 60 DAS and presented in Table 2 and Figure 3. Significantly highest spread $(49.75 \mathrm{~cm})$ was recorded in the treatment $\mathrm{T}_{11}$ receiving $100 \%$ RDF along with rhizobium and micronutrients spray. Minimum plant spread $(41.29 \mathrm{~cm})$ was observed in the treatment $\mathrm{T}_{1}$ receiving $50 \%$ RDF without rhizobium and micronutrients.

The results revealed that the number of branches per plant was maximum due to the combined application of $100 \%$ RDF with rhizobium and micronutrient as compared to other treatments trial in the experiment. This clearly indicates that application of recommended doses of chemical fertilizers along with rhizobium and micronutrient had a cumulative effect to enhance the requirement as well as utilization by the crop for development of more number of branches. The nutrient requirement of the plant supplied through recommend dose of fertilizer along with rhizobium and micronutrient, which increased the growth and hence there was development of number of branches per plant. This finding corroborates with the findings of Kumar et al., (2009).

Number of leaves plant ${ }^{-1}$ was also recorded at 60 DAS and presented in Table 2 and Figure 4. Significantly maximum number of leaves (17.7) was recorded in $\mathrm{T}_{11}$ receiving $100 \%$ of RDF with rhizobium culture and micronutrient. Minimum number of leaves (13.43) at 60DAS was recorded in $T_{1}$ receiving only $50 \%$ RDF without rhizobium culture and micronutrient. The Table 2 and 
Figure 4 clearly indicate relatively lower number of leaves in the treatments receiving only chemical fertilizer without rhizobium and micronutrient.

It is well known that the leaves are the major site of photosynthesis and act as the "Source" and "Sink". The production of leaves is greatly influenced both by environment as well as application of nutrients. In the present study the number of leaves per plant showed significant variations due to various levels of application of inorganic fertilizers along with rhizobium and micronutrients. The combined application of $100 \%$ RDF rhizobium and micronutrient resulted in the maximum production of leaves per plant at 60 DAS. Similar positive effect was also recorded by Indra Kumar and Chauhan, (2009) and Ramana et al., (2010).

The leaf areas of different treatments were recorded and presented in Table 2 and Figure 5. Significantly maximum leaf area was observed in $\mathrm{T}_{11}(163.27 \mathrm{sq} \mathrm{cm})$, which was significantly superior to rest of the treatments. However the lowest value was found in $T_{1}$ $(85.83 \mathrm{sq} \mathrm{cm})$ which was significantly inferior to rest of the treatments of the trial.

The expansion of leaf area is one of the indications of growth in different nutritional investigations which directly influenced the photosynthetic potentiality of the plant. From the present investigation it was seen there was a significant effect on increasing the leaf area by applying $100 \%$ of RDF with rhizobium and micronutrient than other treatments. Application of chemical fertilizer with rhizobium and micronutrient expressed significant superiority over control. The large leaf area might have contributed to the higher value of the leaf dry weight in French bean grown with application of potassium which influenced the leaf area. The results are in conformity with those of Hamid et al., (1990) in mung bean, Ashrat and Karim (1990) in black gram, Johnson and Wallingford (1983) in soybean and Ramana et al., (2010).

Table.1 The experiment comprised of the following treatments

\begin{tabular}{|c|l|}
\hline Treatments & Treatment details \\
\hline $\mathbf{T}_{\mathbf{1}}$ & $50 \%$ of RDF \\
\hline $\mathbf{T}_{\mathbf{2}}$ & $100 \%$ of RDF \\
\hline $\mathbf{T}_{\mathbf{3}}$ & $150 \%$ of RDF \\
\hline $\mathbf{T}_{\mathbf{4}}$ & $50 \%$ of RDF + Rhizobium culture \\
\hline $\mathbf{T}_{\mathbf{5}}$ & $100 \% \mathrm{RDF}+$ Rhizobium culture \\
\hline $\mathbf{T}_{\mathbf{6}}$ & $150 \%$ of RDF + Rhizobium culture \\
\hline $\mathbf{T}_{\mathbf{7}}$ & $50 \%$ of RDF + Micronutrient \\
\hline $\mathbf{T}_{\mathbf{8}}$ & $100 \%$ of RDF + Micronutrient \\
\hline $\mathbf{T}_{\mathbf{9}}$ & $150 \%$ of RDF + Micronutrient \\
\hline $\mathbf{T}_{\mathbf{1 0}}$ & $50 \%$ of RDF + Rhizobium culture + Micronutrient \\
\hline $\mathbf{T}_{\mathbf{1 1}}$ & $100 \%$ of RDF + Rhizobium culture + Micronutrient \\
\hline $\mathbf{T}_{\mathbf{1 2}}$ & $150 \%$ of RDF + Rhizobium culture + Micronutrient \\
\hline
\end{tabular}


Table.2 Effect of fertilizer levels, rhizobium and micronutrient on growth parameters in French bean var. Harsh at 60 DAS

\begin{tabular}{|c|c|c|c|c|c|c|}
\hline Treatment & Treatment detail & $\begin{array}{c}\text { Plant } \\
\text { height } \\
(\mathrm{cm})\end{array}$ & $\begin{array}{c}\text { No. of } \\
\text { branches } \\
\text { per plant }\end{array}$ & $\begin{array}{c}\text { Plant } \\
\text { spread } \\
(\mathrm{cm})\end{array}$ & $\begin{array}{c}\text { No. of } \\
\text { leaves } \\
\text { per plant }\end{array}$ & $\begin{array}{l}\text { Leaf area } \\
\quad\left(\mathrm{cm}^{2}\right)\end{array}$ \\
\hline $\mathbf{T}_{1}$ & $50 \%$ of RDF & 37.38 & 13.23 & 41.29 & 13.43 & 85.83 \\
\hline $\mathbf{T}_{2}$ & $100 \%$ of RDF & 38.16 & 15.10 & 42.48 & 13.63 & 89.93 \\
\hline $\mathbf{T}_{3}$ & $150 \%$ of RDF & 38.61 & 15.80 & 43.28 & 14.43 & 101.40 \\
\hline $\mathbf{T}_{4}$ & $50 \%$ of RDF + Rhizobium culture & 36.11 & 15.60 & 41.71 & 14.10 & 104.57 \\
\hline $\mathbf{T}_{5}$ & $100 \%$ RDF + Rhizobium culture & 39.69 & 15.93 & 44.48 & 14.60 & 106.97 \\
\hline $\mathbf{T}_{6}$ & $150 \%$ of RDF + Rhizobium culture & 41.70 & 16.80 & 45.31 & 15.37 & 111.10 \\
\hline $\mathbf{T}_{7}$ & $50 \%$ of RDF + Micronutrient & 40.18 & 15.93 & 44.69 & 14.60 & 108.53 \\
\hline $\mathbf{T}_{8}$ & $100 \%$ of RDF + Micronutrient & 38.55 & 16.08 & 45.06 & 14.77 & 112.53 \\
\hline $\mathbf{T}_{9}$ & $150 \%$ of RDF + Micronutrient & 42.03 & 16.93 & 45.42 & 15.40 & 119.33 \\
\hline $\mathbf{T}_{10}$ & $50 \%$ of RDF + Rhizobium culture + Micronutrient & 39.96 & 16.60 & 45.38 & 14.83 & 117.13 \\
\hline $\mathbf{T}_{11}$ & $100 \%$ of RDF + Rhizobium culture + Micronutrient & 47.96 & 20.17 & 49.75 & 17.70 & 163.27 \\
\hline \multirow[t]{5}{*}{$\mathbf{T}_{12}$} & $150 \%$ of RDF + Rhizobium culture + Micronutrient & 41.39 & 16.70 & 45.42 & 14.87 & 121.37 \\
\hline & $\operatorname{Sem}( \pm)$ & 1.74765 & 0.8324 & 0.8219 & 0.520 & 12.110 \\
\hline & CD 5\% & 5.12523 & 2.4414 & 2.4103 & 1.526 & 35.514 \\
\hline & CV \% & 7.54059 & 8.8787 & 3.1974 & 6.088 & 18.765 \\
\hline & 'F' test & $\mathbf{S}$ & $\mathbf{S}$ & $\mathbf{S}$ & $\mathbf{S}$ & $\mathbf{S}$ \\
\hline
\end{tabular}




\section{Effect of levels of fertilizer, rhizobium and micronutrients on plant height of French bean var. Harsh at 60 DAS}

49.0

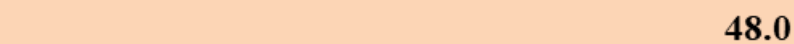

47.0

45.0

43.0

41.7

42.0

41.0

39.7

39.0

37.0

35.0
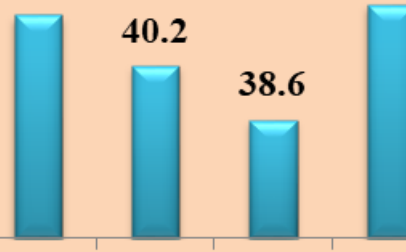

41.4

36.1

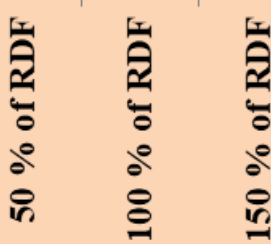

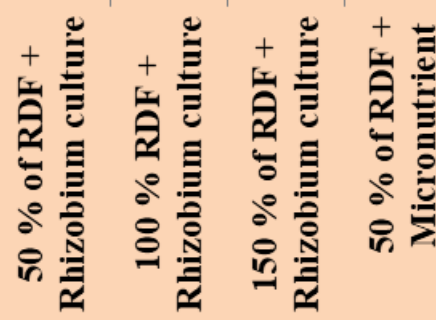

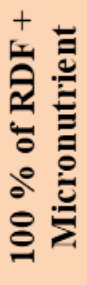
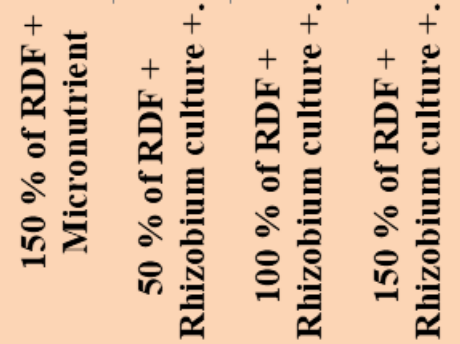

Fig.1 Effect of levels of fertilizer, rhizobium and micronutrient on plant height of

French bean var. Harsh at 60 DAS

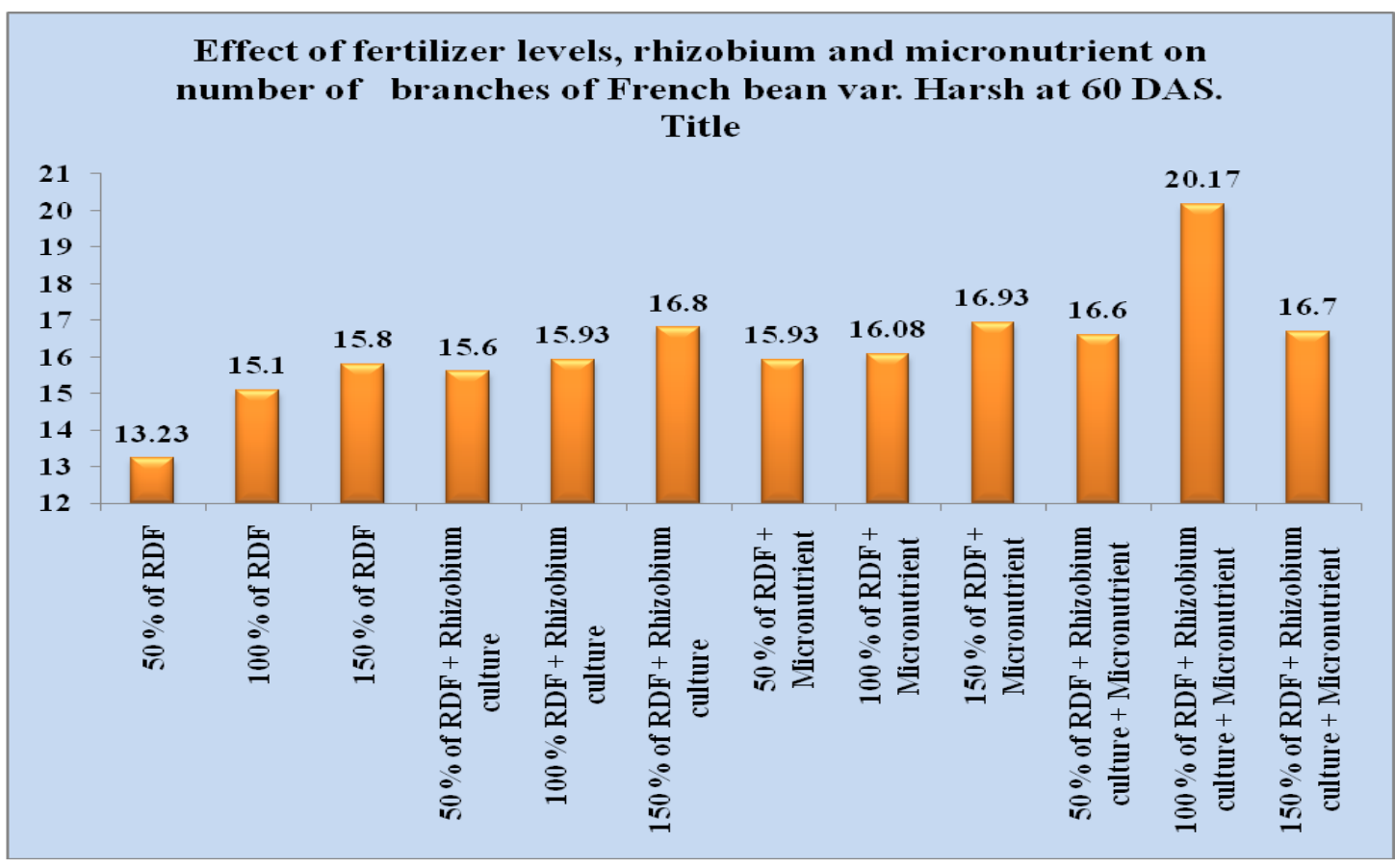

Fig.2 Effect of levels of fertilizer, rhizobium and micronutrient on number of branches of French bean var. Harsh at 60 DAS 


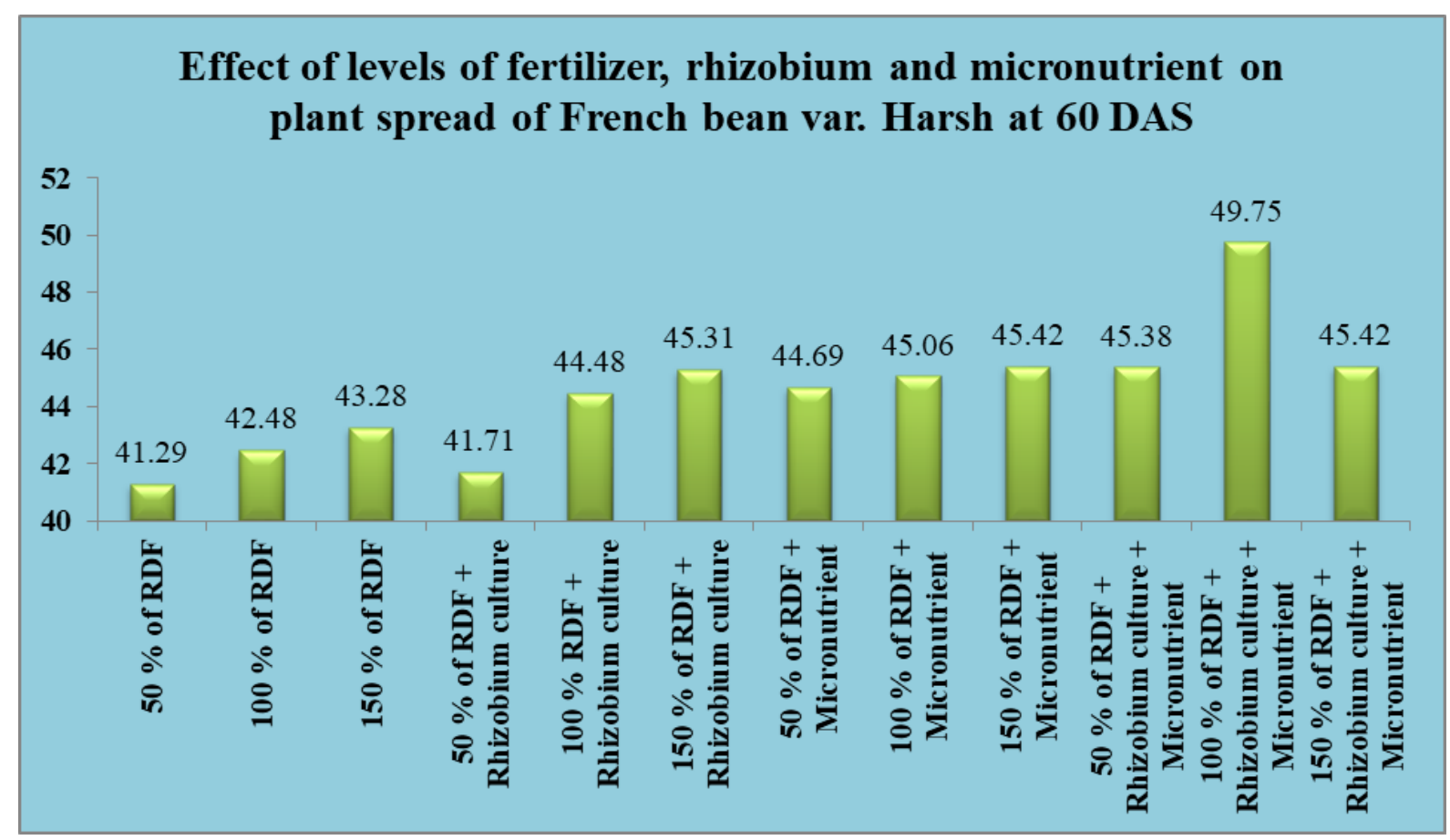

Fig.3 Effect of levels of fertilizer, rhizobium and micronutrient on plant spread of French bean var. Harsh

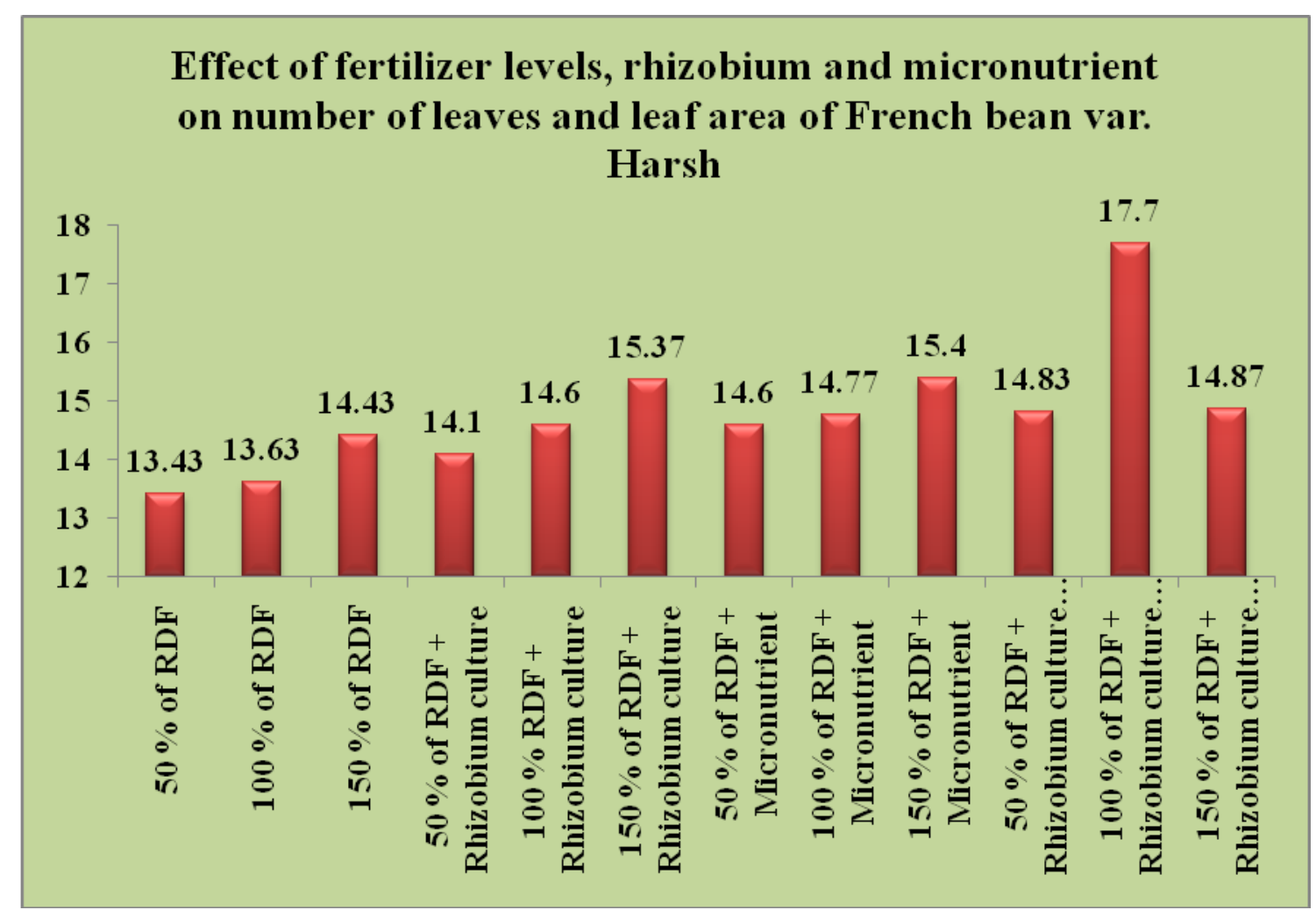

Fig.4 Effect of levels of fertilizer, rhizobium and micronutrient on number of leaves of French bean var. Harsh at 60 DAS 


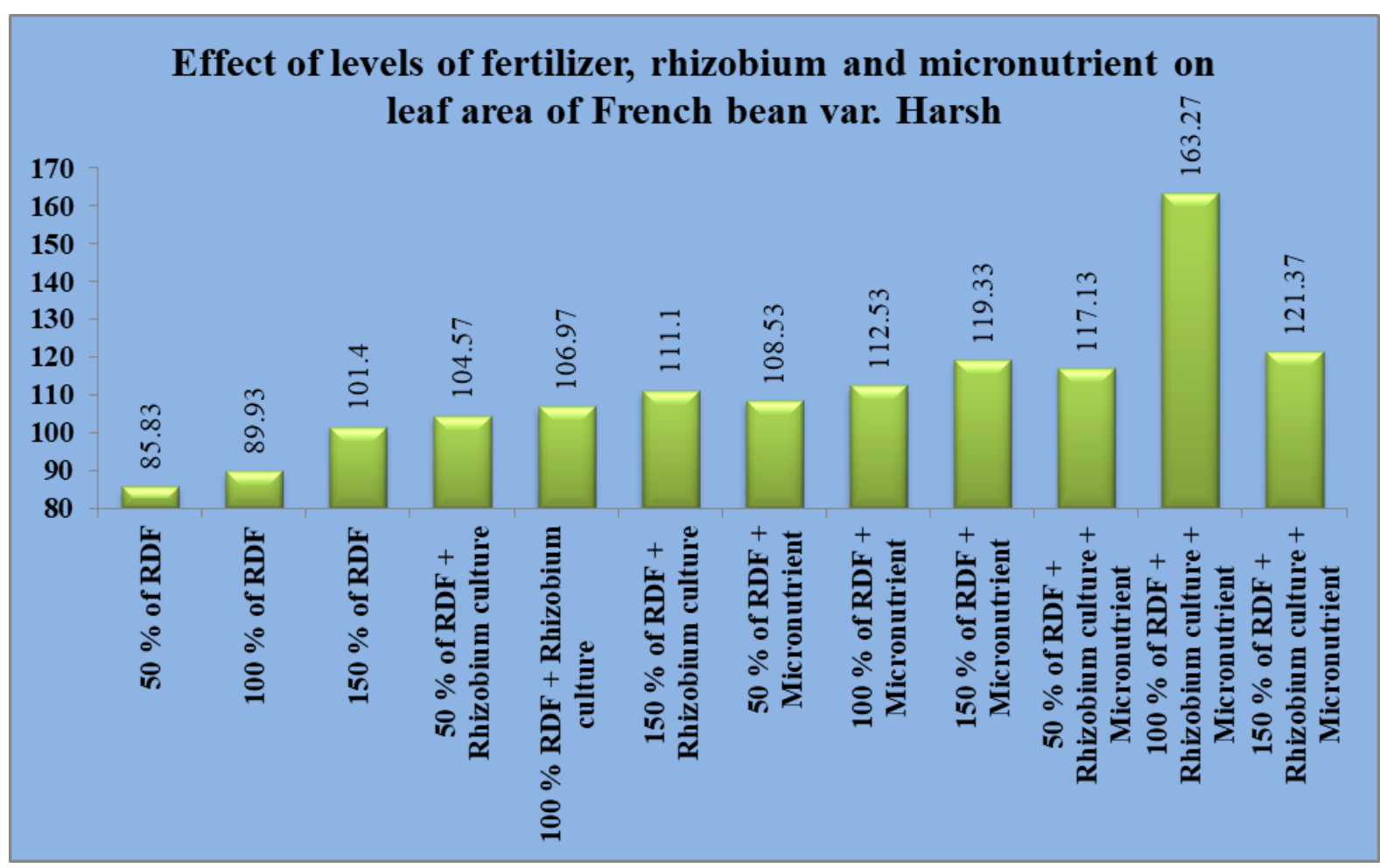

Fig.5 Effect of levels of fertilizer, rhizobium and micronutrient on leaf area of French bean var. Harsh

The salient findings of the present study, entitled "Effect of macronutrients, micronutrients and rhizobium on growth parameter in French bean (Phaseolus vulgaris L.)" clearly indicates that significant variation having highest plant height of $47.96 \mathrm{~cm}$ was recorded in the treatment receiving $100 \%$ RDF (50:75:75 NPK kg ha ${ }^{-1}$ ) in combination with rhizobium treatment and micronutrient spray. Also Significantly maximum number of branches (20.17), highest spread (49.75 $\mathrm{cm})$, maximum number of leaves (17.7) and maximum leaf area(163.27 sq $\mathrm{cm})$ was also observed in the above treatment. Which all were significantly superior to rest other treatments. Increase in vegetative growth characters in above treatment might be the due to the combined effect of rhizobium $(30 \mathrm{~g} / \mathrm{kg}$ seed) and micronutrients (Multiplex) @ $0.1 \%$ with different levels of $\mathrm{N}: \mathrm{P}: \mathrm{K} \mathrm{kg} \mathrm{ha}{ }^{-1}$ which in turn expressed better growth and development in French bean.

\section{References}

Ahmad, I., Ahmad, N., Khan, M.A. and Khan, S., 2016. Influence of rhizobium inoculation on nodules, growth and yield of French bean cultivars. International Journal of Biosciences., 9(6): 226-233.

Ahmad, U., Wali, R., Ilyas, N., Batool, N. and Gul, R., 2015. Evaluation of Compost with different NPK level on pea plant under drought stress, Pure Appl. Biol., 4(2): 261-267.

Ashrat, M. and Karim, F., 1990. Screening of some cultivars or lines of black gram for resistant to water stress. Trop.Agric., 68: 57-62.

Hamid, A.F., Kubota, A.W. and Morokuma, M., $\quad 1990 . \quad$ Photosynthesis, transpiration, dry matter accumulation and yield performance of mung bean plant in response to water stress, $J$. Fac. Agr. Kyush Univ., 35: 81-92. 
Indrakumar, S.N. and Chauhan, J.S., 2009. Response of French bean (Phaseolus vulgaris $L$.) to organic manures and inorganic fertilizer on growth and yield parameters under irrigated condition. Nature and Science., 7(5): $1545-1740$.

Johnson, J.W. and Wallingford., 1983. Weather stress yield loss proper fertilization reduces the risk. Crops Soils Mag., 35: 15-18.

Kakon, S.S., Bhuiya, M.S.U., Hossain, S.M.A., Naher, Q. and Bhuiyan, M.D.H., 2016. Effect of nitrogen and phosphorus on growth and seed yield of French bean, Bangladesh journal Agricultural Research., 41(4): 759772.

Kumar, R.P., Singh, O.N., Singh, Y., Dwivedi, S. and Singh, J.P., 2009. Effect of integrated nutrient management on growth, yield, nutrient uptake and economics of French bean (Phaseolus vulgaris L), Indian Journal of Agricultural Sciences., 79 (2): 122-128.

Ramana, V., Ramarishna, M., Purushotham, K., Balakrishna and Reddy, K., 2010. Effect of biofertilizer on growth, yield attributes and yield of French bean (Phaseolus vulgaris L.), Legume Res., 33(3): 178-183.

Rawat, S., Rana, R., Dhyani, K. and Sahni, S., 2018. Isolation of Rhizobium from root nodules of Pisum Sativum and its biofertilizer. Indian J. Agric. Pure \& Applied Sciences- Botany, 37(1): 2731.

Tiwari, S., Chouhan, R.K., Singh, R., Sukla, R. and Gaur, R., 2017. Integrated Effect of Rhizobium and Azatobactor Culture on the Leguminous Crop Black Gram (Vigna Mungo), Adv Crop Sci Tech., (5):3.

\section{How to cite this article:}

Nitish Kumar Jena, Ajoy Kumar Pattnaik, Premananda Mahapatra, Alok Nandi, Janmejaya Panda and Asim Abhishek Swain. 2020. Effect of Macronutrients, Micronutrients and Rhizobium on Growth Parameters in French Bean (Phaseolus vulgaris L.). Int.J.Curr.Microbiol.App.Sci. 9(04): 1005-1013. doi: https://doi.org/10.20546/ijcmas.2020.904.119 